\title{
Could Patients Older than 75 Years Benefit from a Systematic Breast Cancer Screening Program?
}

\author{
ANNA ILENKO ${ }^{1}$, FABRICE SERGENT ${ }^{1}$, ANTONIN MERCUZOT ${ }^{1}$, MICKAËL ZITOUN ${ }^{2}$, \\ BRUNO CHAUFFERT ${ }^{3}$, ARTHUR FOULON ${ }^{1}$, JEAN GONDRY ${ }^{1}$ and JULIEN CHEVREAU ${ }^{1}$ \\ ${ }^{1}$ Department of Gynecology, University Hospital of Amiens, Amiens, France; \\ ${ }^{2}$ Department of Radiology, University Hospital of Amiens, Amiens, France; \\ ${ }^{3}$ Department of Medical Oncology, University Hospital of Amiens, Amiens, France
}

\begin{abstract}
Background/Aim: To assess prognosis of women aged 75 and older according to breast cancer (BC) diagnosis circumstances. Patients and Methods: A retrospective cohort study was conducted in the Amiens, France, regional oncologic referral center between 2005 and 2015. Two groups were formed depending on whether the patients followed clinical manifestations $(C M)$ or a prescribed systematic mammography (SM). Results: Three hundred and ninentythree patients were selected.CM and SM represented $72 \%$ and $14.5 \%$ of BC diagnosis circumstances, respectively. In the SM group statistically significant differences included: earlier stage cancer diagnosis (tumor stages 0 and 1 accounted for $6.3 \%$ and $61.4 \%$ of cases, respectively), less lymph node invasions (35.7\% and $8.8 \%$ ) and metastases (19.1\% and $0 \%$ ), more frequent possibility of conservative surgery $(25.6 \%$ and $74.5 \%$ ), improved global and disease-free survival rates (by 14.2 and 18.4 months). Conclusion: Screening seems to improve prognosis of older BC patients; this constitutes a strong argument for reconsidering age limits of national $B C$ screening programs.
\end{abstract}

In several countries, women aged between 50 to 74 years are eligible to government-supported mammographies every two years as part of national breast cancer prevention programs. Even though it is sometimes questioned, organized screening is now the subject of a consensus for this age group in terms of public health benefits $(1,2)$. Recently however, there has been a growing demand for extensions of such programs, concomitant of significant increase in life quality and

Correspondence to: Julien Chevreau, MD, Department of Gynecology, Avenue Laennec, CHU Amiens Sud, 80054 Amiens Cedex 1, France. Tel: +330322087400, e-mail: chevreau.julien@chuamiens.fr

Key Words: Breast cancer, older woman, screening program, screening extension. expectancy for older women (3). Current literature regarding breast cancer (BC) screening after 70 years is poor, and no patient older than 75 years was ever included in a large randomized screening trial (4). Therefore is essential to better study breast cancer in elderly patients as it is far from a negligible entity (5).

In this context, the work in this study was conducted. Based on 10 years of $\mathrm{BC}$ diagnosis in patients aged of at least 75 years, we aimed to determine how histological type, stage, treatment, mortality and survival with and without recurrence were impacted by discovery circumstances. The aim was to determine if prognosis varied whether cancer was diagnosed following systematic mammography (SM) or clinical manifestation $(\mathrm{CM})$.

\section{Patients and Methods}

Patients. In this study, the cohort was derived from the retrospective analysis of all $\mathrm{BC}$ patients aged 75 years or older, referred to the Breast Unit of the Amiens, France, University Hospital from January the 1st, 2005 to December the 31st, 2015. Cut-off age was chosen based on French recommendations stipulating that systematic BC screening should not be continued beyond 75 for asymptomatic patients. Data collection was achieved using the computerized record of weekly oncologic multidisciplinary meetings, where all $\mathrm{BC}$ cases, without exception, are examined. Patients were referred by their general practitioner, their gynecologist or sought counsel from the hospital at their own initiative. All BC diagnoses were biopsy-proven after initial breast imaging.

Subjects were divided into two groups depending on whether BC diagnosis was established following individualized screening, that is to say through a systematic mammography (SM) prescribed without specific clinical context, or following clinical manifestation (CM). The latter were defined as palpation of a breast mass or lymphadenopathy in a usual BC drainage territory, discovery of a clinically inflammatory breast, or altered general condition suggestive of cancerous origin.

The following situations were excluded from analysis: incidental $\mathrm{BC}$ diagnoses (medical testing leading to diagnosis conducted towards another purpose); unspecified BC diagnosis circumstances; and, lastly, prior personal history of $\mathrm{BC}$. 
Table I. Patients' characteristics and distributions according to diagnosis circumstances.

\begin{tabular}{|c|c|c|c|}
\hline & $\begin{array}{c}\text { Clinical } \\
\text { manifestations }\end{array}$ & $\begin{array}{c}\text { Systematic } \\
\text { mammography }\end{array}$ & $p$-Value \\
\hline Patients (n, \%) & $283 / 393(72.0 \%)$ & $57 / 393(14.5 \%)$ & $p<0.05^{*}$ \\
\hline $\begin{array}{l}\text { Age at diagnosis } \\
\text { (years, } \pm \text { SD) }\end{array}$ & $82.2 \pm 4.8$ & $79.0 \pm 4.6$ & $p<0.05^{*}$ \\
\hline \multicolumn{4}{|c|}{$\begin{array}{l}\text { Histologic subtypes } \\
(\mathrm{n}, \%)\end{array}$} \\
\hline IDC & $214(75.6 \%)$ & $31(54.4 \%)$ & $p<0.05^{*}$ \\
\hline ILC & $28(9.9 \%)$ & $8(14 \%)$ & $p=0.35$ \\
\hline DCIS & $4(1.4 \%)$ & $13(22.8 \%)$ & $p<0.05^{*}$ \\
\hline Others & $37(13.1 \%)$ & $5(8.8 \%)$ & $p=0.37$ \\
\hline \multicolumn{4}{|l|}{ Size $(n, \%)$} \\
\hline Tis & $4(1.4 \%)$ & $13(22.8 \%)$ & $p<0.05^{*}$ \\
\hline $\mathrm{T} 1$ & $42(14.8 \%)$ & $35(61.4 \%)$ & $p<0.05^{*}$ \\
\hline $\mathrm{T} 2$ & $126(44.5 \%)$ & $6(10.5 \%)$ & $p<0.05^{*}$ \\
\hline $\mathrm{T} 3$ & $20(7.1 \%)$ & $3(5.3 \%)$ & $p=0.62$ \\
\hline $\mathrm{T} 4$ & $56(19.8 \%)$ & 0 & $p<0.05^{*}$ \\
\hline Unknown & $35(12.4 \%)$ & 0 & $p<0.05^{*}$ \\
\hline \multicolumn{4}{|c|}{ Nodal status (n, \%) } \\
\hline No & $120(42.4 \%)$ & $52(91.2 \%)$ & $p<0.05^{*}$ \\
\hline N1 & $87(30.7 \%)$ & $2(3.5 \%)$ & $p<0.05^{*}$ \\
\hline $\mathrm{N} 2$ & $4(1.5 \%)$ & $2(3.5 \%)$ & $p=0.27$ \\
\hline N3 & $10(3.5 \%)$ & $1(1.8 \%)$ & $p=0.49$ \\
\hline Unknown & $62(21.9 \%)$ & 0 & $p<0.05^{*}$ \\
\hline \multicolumn{4}{|c|}{ Metastatic status (n, \%) } \\
\hline M0 & $211(74.5 \%)$ & $57(100 \%)$ & $p<0.05^{*}$ \\
\hline M1 & $54(19.1 \%)$ & 0 & $p<0.05^{*}$ \\
\hline Unknown & $18(6.4 \%)$ & 0 & $p=0.05$ \\
\hline \multicolumn{4}{|c|}{ Tumor stage (n, \%) } \\
\hline 0 & $4(1.4 \%)$ & $13(22.8 \%)$ & $p<0.05^{*}$ \\
\hline I & $14(4.9 \%)$ & $22(38.6 \%)$ & $p<0.05^{*}$ \\
\hline IIa & $77(27.2 \%)$ & $7(12.3 \%)$ & $p<0.05^{*}$ \\
\hline $\mathrm{IIb}$ & $45(15.9 \%)$ & $4(7 \%)$ & $p=0.08$ \\
\hline IIIa & $9(3.2 \%)$ & $3(5.3 \%)$ & $p=0.44$ \\
\hline IIIb & $31(11 \%)$ & $1(1.8 \%)$ & $p<0.05^{*}$ \\
\hline IV & $48(17 \%)$ & 0 & $p<0.05^{*}$ \\
\hline Unknown & $55(19.4 \%)$ & $7(12.2 \%)$ & $p=0.20$ \\
\hline \multicolumn{4}{|c|}{ Histological grade (n, \%) } \\
\hline I & $60(21.2 \%)$ & $18(31.6 \%)$ & $p=0.09$ \\
\hline II & $136(48.1 \%)$ & $22(38.6 \%)$ & $p=0.19$ \\
\hline III & $56(19.7 \%)$ & $9(15.8 \%)$ & $p=0.48$ \\
\hline Unknown & $31(11 \%)$ & $8(14 \%)$ & $p=0.51$ \\
\hline
\end{tabular}

SD, Standard deviation; IDC, infiltrating ductal carcinoma; ILC, infiltrating lobular carcinoma; DCIS, ductal carcinoma in situ. Statistically significant differences

Analyzed variables for both groups were: age at diagnosis, histological tumor type (based on the Scarff, Bloom and Richardson classification) and grade (according to the International Union Against Cancer's TNM classification system), tumor size, nodal and metastasis status, overall and cancer-specific mortalities as well as overall and disease-free survivals. Our database also specified whether surgery was part of management, as well as its type (conservative or not).

All patients were managed according to a multidisciplinary decision, after a systematic onco-geriatric assessment, based on French
Table II. Surgical management and type according to diagnosis circumstances.

\begin{tabular}{lccc}
\hline & $\begin{array}{c}\text { Clinical } \\
\text { manifestations }\end{array}$ & $\begin{array}{c}\text { Systematic } \\
\text { mammography }\end{array}$ & $p$-Value \\
\hline $\begin{array}{c}\text { Patients managed } \\
\text { surgically (n, \%) }\end{array}$ & $195(68.9 \%)$ & $55(96.5 \%)$ & $p<0.05^{*}$ \\
$\begin{array}{c}\text { Type of surgical } \\
\text { management (n, \%) }\end{array}$ & $50(25.6 \%)$ & $41(74.5 \%)$ & $p<0.05^{*}$ \\
$\begin{array}{c}\text { Conservative } \\
\text { (lumpectomy + SL) }\end{array}$ & $145(74.4 \%)$ & $14(25.5 \%)$ & $p<0.05^{*}$ \\
$\begin{array}{c}\text { Invasive (mastectomy } \\
\text { and/or AD) }\end{array}$ & & & \\
\hline
\end{tabular}

SL, Sentinel lymphadenectomy; AD, axillary dissection. Statistically significant differences.

national guidelines at time of diagnosis. This included surgical indications and procedures that were only performed, in this age group, in a curative perspective. They consisted of either lumpectomy or mastectomy, associated with sentinel lymphadenectomy (SL) or/and axillary dissection (AD), depending on the context. Our results regarding surgical techniques employed were divided into two groups: a "conservative surgery" group consisting of lumpectomy and SL, and an "invasive surgery" group comprising at least one radical technique (mastectomy or AD). A patient initially included in the first group who underwent $\mathrm{AD}$ following the histological extemporaneous analysis of a SL was automatically switched to the invasive group. A histological analysis was systematically conducted following surgical procedure.

Mortality was divided into two categories: overall and BCspecific mortality. The latter was defined as death considered directly related to the disease or its complications (malnutrition, pulmonary embolism...), while non-specific mortality concerned other causes of death unrelated to BC.This information was collected through our institution's centralized medical computerized record or by direct contact with the referring physician. Recurrence as well as overall and disease-free survival periods were obtained in the same manner.

All research linked to this study was approved by the institutional board of the Amiens University Hospital in France.

Statistical analysis. A descriptive statistical analysis was performed to describe the cohort. Time intervals were expressed in months, rounded to the nearest whole number, and represented time span between $\mathrm{BC}$ diagnosis and the studied event: death, recurrence, total follow-up time. Qualitative variables were expressed as " $n$ " and percentages, and quantitative variables were expressed as their mean value and standard deviation. Chi2 and Fisher exact tests were used to compare qualitative variables, with a significance threshold set up at $p<0.05$. To calculate and compare survival rates, KaplanMeier analysis with Mantel-Cox log-rank tests were used.

\section{Results}

General. During the ten-year study, 393 patients who were 75 years or older were treated for BC in our Institution. Diagnosis was established as a result of $\mathrm{CM}$ in $72 \%$ of cases, following 
Ilenko et al: A Systematic Breast Cancer Screening Program for Older Women?

Table III. Overall and breast cancer specific mortalities; overall and disease-free average survivals.

\begin{tabular}{lccc}
\hline & $\begin{array}{c}\text { Clinical } \\
\text { manifestations }\end{array}$ & $\begin{array}{c}\text { Systematic } \\
\text { mammography }\end{array}$ & 95\% CI \\
\hline Overall mortality (n, \%) & $92(32.5 \%)$ & $6(10.5 \%)$ & $p<0.05^{*}$ \\
2 Years & $40(14.1 \%)$ & $2(3.5 \%)$ & $p<0.05^{*}$ \\
5 Years & $78((27.6 \%)$ & $5(8.8 \%)$ & $p<0.05^{*}$ \\
Specific mortality (n, \%) & $60(21.2 \%)$ & $1(1.8 \%)$ & $p<0.05^{*}$ \\
2 Years & $28(9.9 \%)$ & $1(1.8 \%)$ & $p<0.05^{*}$ \\
5 Years & $51(18 \%)$ & $1(1.8 \%)$ & $p<0.05^{*}$ \\
Overall survival average (months, SD) & $38.6 \pm 32.7$ & $52.8 \pm 30.9$ & $p<0.05^{*}$ \\
Disease-free survival average (months, SD) & $28.3 \pm 33.3$ & $46.7 \pm 30.2$ & {$[3.6 ; 21.7]$} \\
\hline
\end{tabular}

SD, standard deviation; CI, confidence interval. Statistically significant differences.

SM for $14.5 \%$ of patients and incidentally in $3.8 \%$ of cases. For $9.7 \%$ of women treated for BC, discovery circumstances were unknown. Mean age at diagnosis in our cohort was $81.7 \pm 4.8$ years and $82.2 \pm 4.8$ and $79 \pm 4.6$ years when $\mathrm{BC}$ diagnosis occurred in a context of CM and SM. Mean followup duration was 37.4 months for the entire cohort (34.4 and 41.2 months for CM and SM groups, respectively).

Patient and BC characteristics. Patient and BC characteristics according to discovery circumstances are detailed in Table I. $\mathrm{BC}$ discovery mode had no significant impact on proportions of invasive lobular carcinoma (ILC), however when diagnosis was established following SM, invasive ductal carcinoma (IDC) proportions were significantly lower and ductal carcinoma in situ (DCIS) increased compared to women in the CM group. Similarly, in the SM group, patients presented significantly smaller tumor sizes and a higher proportion of absence of lymph node involvement. When BC was discovered in an evocative clinical context, patients were significantly more metastatic as no screened woman presented metastasis. Regarding BC stages, early stages (0 and 1) were more common amongst screened patients, while more advanced stages ( $2 \mathrm{a}, 3 \mathrm{~b}$ and 4$)$ were significantly more frequent in the CM group. In terms of histological grade, there was no difference between the two groups.

Management. Patients in the SM group were more frequently managed surgically, and more often with a conservative procedure in a statistically significant manner (Table II).

Mortality. Overall mortality as well as cancer specific mortalitiy were significantly lower when BC was diagnosed after SM. The same results were observed two and five years after diagnosis. These differences were also found to be statistically significant (Table III).

Overall and disease-free survivals. Mean overall survival for patients whose cancer was diagnosed after SM was significantly greater, with a difference of 14.2 months compared to a discovery following CM $(p<0.05)$. Similarly, in the SM group, a significantly longer disease-free survival was observed compared to the CM group, with an average difference of 18.4 months $(p<0.05)$ (Table III and Figure 1).

\section{Discussion}

Nowadays, life expectancy at 75 years is far from negligible. However, no national BC screening program has ever been set up in any country beyond that age. BC incidence increases with age, including for the elderly, therefore addressing the question of extending prevention guidelines to include that age group seems a priority (6-10).

Before considering extending BC screening to the elderly, disease aggressiveness should be assessed at this age. Hartman et al. have highlighted higher rates of invasive BC after 75 years (22 out of 26 studied cases) in comparison to average reported proportions in the 50-74-year-old patient cohorts (11). Our cohort also presented high rates of invasive disease, but proportions were even greater when diagnosis was established following CM. Our findings corroborate those of Field et al. and show that contrary to what is sometimes reported, BC at an older age is not a slowevolving, almost chronic, disease but at least as aggressive cancer as when diagnosed in younger patients $(12,13)$. Progression of $\mathrm{BC}$ is another fundamental parameter when contemplating screening. Evidence suggests successive steps, from a pre-cancerous stage to a pre-invasive and ultimately, a true invasive disease $(14,15)$. The finding that in our cohort, the SM group presented lower degrees of infiltration (compared to the CM group) suggests that when diagnosis occurred at an earlier stage of the cancer's progression could allow for a precocious management. It is, nevertheless, important to note that prognosis is also conditioned by other factors, notably immunohistochemical cancer profile, which, in patients older than 75 years, may define a less aggressive 

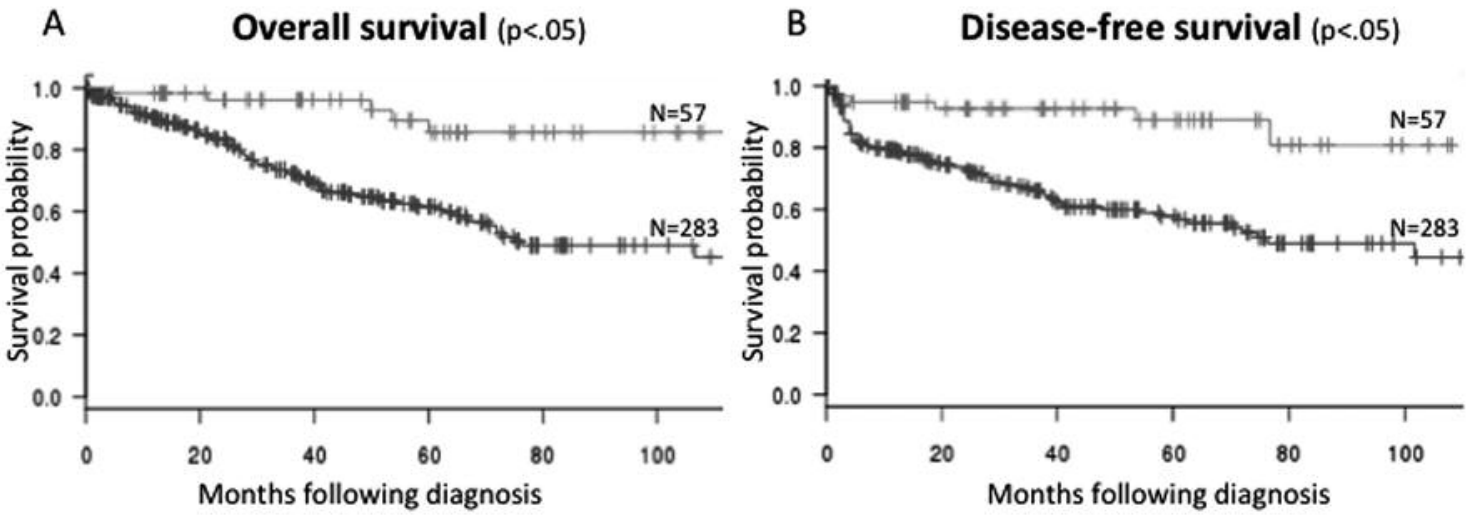

Figure 1. Kaplan-Meier plots of (A) overall and (B) disease-free survivals. In both plots, upper curves indicate systematic mammography (N=57), while lower curves indicate clinical manifestations $(N=283)$. $p$-Values were calculated using the log-rank test.

disease (positivity for oestrogen/progesterone receptors, low proliferative rate, absence of p53 accumulation, bcl-2 overexpression, diploid DNA content) $(16,17)$.

A successful BC prevention program is defined by its capacity to detect disease at its earlier stages. Regarding older patients, it was showed that early-stage BC is detected less frequently compared to younger women, essentially due to lack of screening (18). In their work, Molino et al. have shown a rate of $\mathrm{T} 1$ tumors at diagnosis of $70 \%$ for $\mathrm{BC}$ patients between 45 and 64 years of age and of only $47 \%$ after 75 years (19). In our cohort, these numbers were higher in the screened group, as $61.4 \%$ of $\mathrm{BC}$ were $\mathrm{T} 1$ tumors (versus $14.8 \%$ in the CM group), thus suggesting an earlier diagnosis when a SM was performed. Consequences were also observed in terms of management, as patients with earlier BC stages in the SM group benefited more often from surgery, which implied a curative perspective. Certain authors argue that surgery is not a reasonable option in older patients, but global BC operative mortality in this population, remains low, estimated at $1-2 \%(8)$. This seems to be an acceptable risk if a curative perspective is contemplated, though indications should be modulated after a comprehensive assessment of associated comorbidities. Furthermore, earlier detection in our SM group appeared to enable higher proportions of conservative management, as $74.5 \%$ of our surgically treated screened population had neither mastectomy nor AD. Minimally invasive techniques are especially attractive in this age group, as they allow shorter hospitalizations and faster rehabilitations, which are correlated to lower rates of autonomy loss and overall less morbidity $(20,21)$. Invasive surgery is not the only type of cancer management associated with high morbidity rates. Chemotherapy also has a significant impact, particularly in older patients who usually present lower tolerance levels to the many listed side-effects (22). Our data showed no metastatic BC in the patient group who had benefited from SM, with a statistically significant difference compared to women presenting CM. These important findings are signifying a lower specific mortality for the screened women, a lesser need for chemotherapy and therefore, a lower treatment-induced morbidity.

Studies investigating mortality in older patients with BC are scarce. Our data showed that overall and specific mortalities were higher when diagnosis was the result of CM.The same conclusions were made by Barco et al. who also viewed mass screening as an improvement for women older than 69 years (23). Furthermore, differences of overall and disease-free survivals were both statistically as well as clinically significant. Indeed, estimated at 14.2 and 18.4 months respectively in our series, this represents a noticeable gain in terms of life expectancy in the SM group, especially for older patients.

Methodological limits stem from retrospective analyses and ours should be mentioned, as well. Indeed, the aim of our study was to obtain a comprehensive record of all treated $\mathrm{BC}$ in our oncologic referral center. Thus, patients in the two groups were not paired for comorbidities. This could represent a bias as it can be anticipated that patients receiving regular mammographies may also benefit from closer medical monitoring and are, thereby, more likely to receive better care for their potential associated diseases. This confounding factor should nonetheless be put into perspective, as in organized mass screenings the less observant patients are also the most isolated in terms of medical coverage (24).

In conclusion, our results constitute a strong argument for reconsidering age limits of national BC screening programs as this could imply important benefits for older patients in terms of reduction of mortality and treatment-induced morbidity. 


\section{References}

1 Gøtzsche P and Olsen O: Is screening for breast cancer with mammography justifiable? The Lancet 355: 129-134, 2000.

2 Note de cadrage.Dépistage du cancer du sein chez les femmes de 40 à 49 ans et de 70 à 79 ans en France. Haute Autorité de Santé 2013. Available online from: http://www. has-sante.fr.

3 Blanpain N: L'espérance de vie s'accroît, les inégalités sociales face à la mort demeurent. Insee Première no. 1372, 2011.

4 Yen A, Duffy S, Chen T, Chen LS, Chiu SY, Fann JC, Wu WY, Su CW, Smith RA and Tabár L: Long-term incidence of breast cancer by trial arm in one county of the Swedish Two-County Trial of mammographic screening. Cancer 118: 5728-5732, 2012.

5 Binder-Foucard F, Belot A, Delafosse P, Remontet L, Woronoff A and Bossard N: Estimation nationale de l'incidence et de la mortalité par cancer en France entre 1980 et 2012. Etude à partir des registres des cancers du réseau. Francim 1: 122, 2013

6 Wyld L and Reed M: The role of surgery in the management of older women with breast cancer. Eur J Cancer 43: 2253-2263, 2007.

7 Passage K and McCarthy N: Critical review of the management of early-stage breast cancer in elderly women. Intern Med J 37: 181-189, 2007.

8 Jemal A, Ward E and Thun M: Recent trends in breast cancer incidence rates by age and tumor characteristics among U.S. women. Breast Cancer Res 9: R28, 2007.

9 Eaker S, Dickman P, Bergkvist L, Holmberg L; Uppsala/Orebro Breast Cancer Group. Differences in management of older women influence breast cancer survival: results from a population-based data-base in Sweden. PLoS Med 3: e25, 2006.

10 Thomas A, Weigel R, Lynch C, Spanheimer P, Breitbach E and Schroeder M: Incidence, characteristics, and management of recently diagnosed, microscopically invasive breast cancer by receptor status: Iowa SEER 2000 to 2013. Am J Surg: in press, 2016. doi: 10.1016/j.amjsurg.2016.08.008. [Epub ahead of print]

11 Hartman M, Drotman M and Arleo E: Annual screening mammography for breast cancer in women 75 years old or older: to screen or not to screen. AJR Am J Roentgenol 204: 11321136, 2015.

12 Panjari M, Robinson P, Davis S, Schwarz M and Bell R: A comparison of the characteristics, treatment and outcome after 5 years, of Australian women aged $70+$ with those aged $<70$ years at the time of diagnosis of breast cancer. J Geriatr Oncol 5: 141147,2014

13 Field L, Wilson T, Strawderman M, Gabriel H and Helvie H: Mammographic screening in women more than 64 years old: a comparison of 1- and 2-year intervals. AJR Am J Roentgenol 170: 961-965, 1998.

14 Cowell C, Weigelt B, Sakr R, Ng C, Hicks J and King T: Progression from ductal carcinoma in situ to invasive breast cancer: revisited. Mol Oncol 7: 859-869, 2013.
15 Rivenbark A and Coleman W: Field cancerization in mammary carcinogenesis-implications for prevention and treatment of breast cancer. Exp Mol Pathol 93: 391-398, 2012.

16 Crivellari D, Aapro M, Leonard R, von Minckwitz G, Brain E, Goldhirsch A, Veronesi A and Muss H: Breast cancer in the elderly. J Clin Oncol 25: 1882-1890, 2007.

17 Daidone M, Coradini D, Martelli G and Veneroni S: Primary breast cancer in elderly women: biological profile and relation with clinical outcome. Crit Rev Oncol Hematol 45: 313-325, 2003.

18 Olmi P, Fallai C, Cerrotta A, Lozza L and Badii D: Breast cancer in the elderly: the role of adjuvant radiation therapy. Crit Rev Oncol Hematol 48: 165-178, 2003.

19 Molino A, Giovannini M, Auriemma A, Fiorio E, Mercanti A, Mandarà $\mathrm{M}$, Caldara $\mathrm{A}$, Micciolo R, Pavarana $\mathrm{M}$ and Cetto GL: Pathological, biological and clinical characteristics, and surgical management, of elderly women with breast cancer. Crit Rev Oncol Hematol 59: 226-233, 2006.

20 Madsen A, Haugaard K, Soerensen J, Bokmand S, Friis E and Holtveg H: Arm morbidity following sentinel lymph node biopsy or axillary lymph node dissection: a study from the Danish Breast Cancer Cooperative Group. Breast 17: 138-147, 2008.

21 Chatterjee A, Pyfer B, Czerniecki B, Rosenkranz K, Tchou J and Fisher C: Early postoperative outcomes in lumpectomy versus simple mastectomy. J Surg Res 198: 143-148, 2015.

22 Karavasilis V, Papadimitriou C, Gogas H, Kouvatseas G, Pentheroudakis G, Koutras A, Christodoulou C, Bafaloukos D, Samantas E, Pisanidis N, Papakostas P, Aravantinos G, Karanikiotis C, Kosmidis P, Pectasides D, Dimopoulos MA and Fountzilas G: Safety and tolerability of anthracycline-containing adjuvant chemotherapy in elderly high-risk breast cancer patients. Clin Breast Cancer 16: 291-298, 2016.

23 Barco I, Chabrera C, García, Font M, Gimenez N and Fraile M: Comparison of screened and nonscreened breast cancer patients in relation to age: a 2-institution study. Clin Breast Cancer 15: 482-489, 2015.

24 Da Costa Vieira R, Lourenço T, Mauad E, Moreira Filho V, Peres $\mathrm{S}$ and Silva T: Barriers related to non-adherence in a mammography breast-screening program during the implementation period in the interior of São Paulo State, Brazil. J Epidemiol Glob Health 5: 211219, 2015.
Received December 3, 2016

Revised January 26, 2017

Accepted January 27, 2017 